\title{
DEPOSITION OF CARBON NANOSTRUCTURES BY SURFATRON GENERATED DISCHARGE
}

\author{
Marina Davydova ${ }^{a, *}$, Jiri $\mathrm{Smid}^{b}$, Zdenek Hubicka $^{b}$, Alexander Kromka $^{a}$ \\ ${ }^{a}$ Institute of Physics ASCR, Cukrovarnicka 10, Prague, Czech Republic \\ ${ }^{b}$ Institute of Physics ASCR, Na Slovance 2, Prague, Czech Republic \\ * corresponding author: davydova@fzu.cz
}

\begin{abstract}
Various carbon nanostructures were deposited by surface wave discharge from an $\mathrm{Ar} / \mathrm{CH}_{4} / \mathrm{CO}_{2}$ gas mixture. The type and the form of the carbon nanostructure were controlled by the gas mixture and the gas inlet. The nanostructures that formed were investigated by scanning electron microscopy and by Raman measurements. The influence of the geometrical combination of the gas inlets (via surfatrons or via the gas shower system) into the chamber is found to be a crucial deposition parameter for the controllable growth of desired carbon nanostructures.
\end{abstract}

KEYWORDS: surfatron, carbon nanostructures, microwave plasma, PECVD.

\section{INTRODUCTION}

Plasmas are extremely successful in many industrial thin-film applications, e.g. in the production of microelectronic devices and solar cells [1] and for biomedical applications [2]. Many of these thin-film materials have been successfully developed using mainly empirical methods. Microwave (MW) plasma is frequently used in so-called plasma-enhanced chemical vapor deposition (PECVD). In MW PECVD, the feed gas mixture is ionized and excited by microwave radiation in a reaction chamber. Ionized and exited neutral atomic and molecular components from plasma, generally of low fractional ionization, in which radicals and neutral react and/or recombine and finally condense onto the substrate as a thin film [3]. The commercial and technical value of low temperature plasmas is well established.

Among the broad range of plasmas, surface wave discharge (SWD) is nowadays considered promising as a low-temperature process for depositing various coatings. SWD is widely used in the engineering industries as a source of reactive radicals and for depositing $\mathrm{ZnO}$ thin films, $\mathrm{SiO}_{x} \mathrm{C}_{y} \mathrm{H}$ thin films, semiconductive $\mathrm{SiGe}$ films, and some others [4- 7]. However, deposition of carbon nanostructures by SWD is not broadly used. SWD is characterized by the transport of energy toward an active plasma area by an electromagnetic wave that is spread along the plasma column [7]. The so-called surfatron waveguide can operate both in a continuous regime and in a pulsed regime employing a microwave generator.

Low-temperature MW plasma is a strongly nonequilibrium system generating an exotic physical and chemical environment through free electrons at low gas temperatures. This unique environment allows the treatment of temperature-sensitive materials at molecular precision.

In the present work we investigate the growth of var- ious carbon nanostructures by surface wave discharge. The influence on the deposition process of gas flow rate, gas mixture and the geometrical combination of gas inlets (via surfatrons or via a gas shower system) into the chamber is discussed here.

\section{ExPERIMENTAL DETAILS}

\subsection{Deposition System}

Figure 1 shows the experimental set-up of a modified plasma-enhanced CVD reactor [7]. The plasma system consists of 4 independent nozzles (surfatrons) which form a single SWD. The nozzles are connected to the microwave source $(2.45 \mathrm{GHz})$. The MW generator used here can be operated both in continuous mode and in pulsed mode, with averaged absorbed power of about $300 \mathrm{~W}$ per surfatron and with repetition frequency $f=60 \mathrm{~Hz}$.

The process gases were introduced into the vacuum chamber via surfatrons (1 or 4 nozzles) or via a gas shower. The distance between the sample and the surfatron outlet(s), i.e., the quartz tube, varied in the range from 1 to $3 \mathrm{~cm}$.

\subsection{Deposition OF CARBON NANOSTRUCTURES}

The deposition of the carbon nanostructures comprised three steps:

(1.) A catalyst fabrication step, which employed thermal evaporation of an Ni layer (6 $\mathrm{nm}$ in thickness) on $10 \times 10 \mathrm{~mm}^{2} \mathrm{Si} / \mathrm{SiO}_{2}$ substrates. The thickness of the Ni was monitored by in situ measurements, using a quartz-crystal-based thickness monitor (INFICON XTC/2).

(2.) A thermal treatment step, during which the $\mathrm{Si} / \mathrm{SiO}_{2}$ substrates covered with a catalyst layer were thermally treated in hydrogen plasma using the large area pulsed linear-antenna microwave plasma 


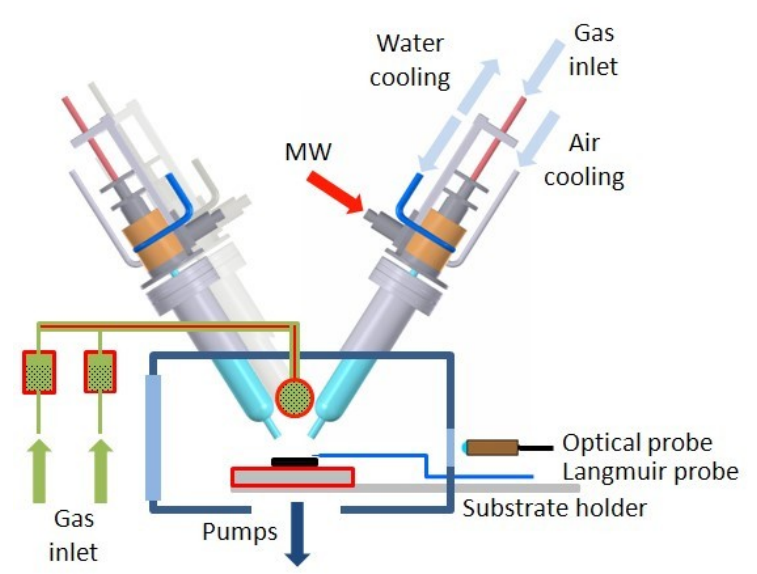

(a)

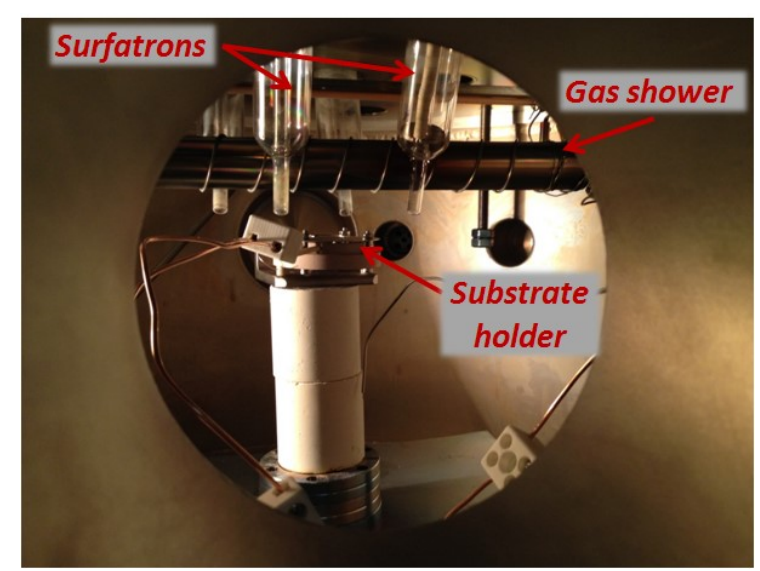

(b)

FiguRE 1. Schematic view of the modified plasma-enhanced CVD surface-wave discharge set-up used for depositing the carbon nanostructures (a) and the digital photography inside the vacuum chamber (b).

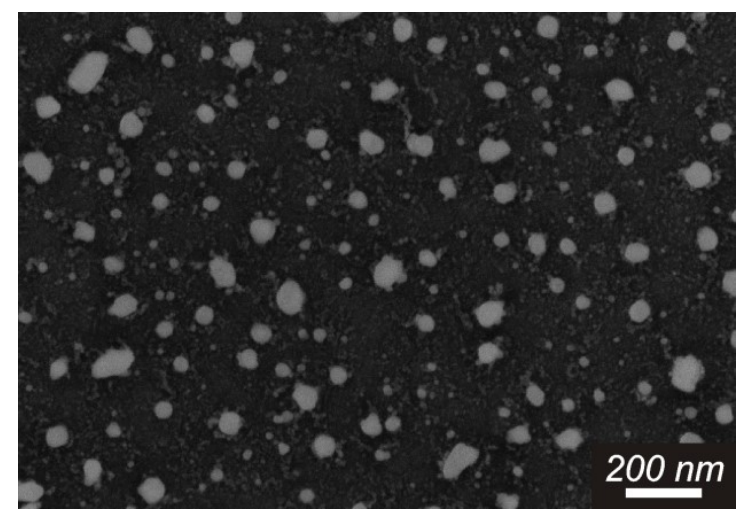

(a)

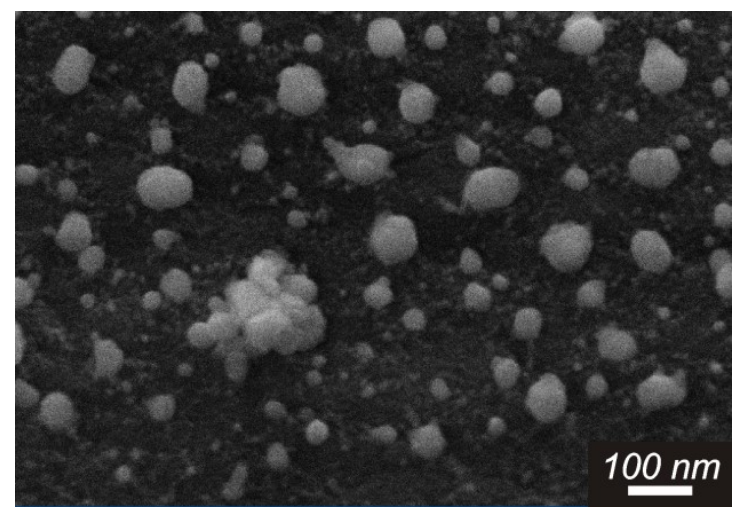

(c)

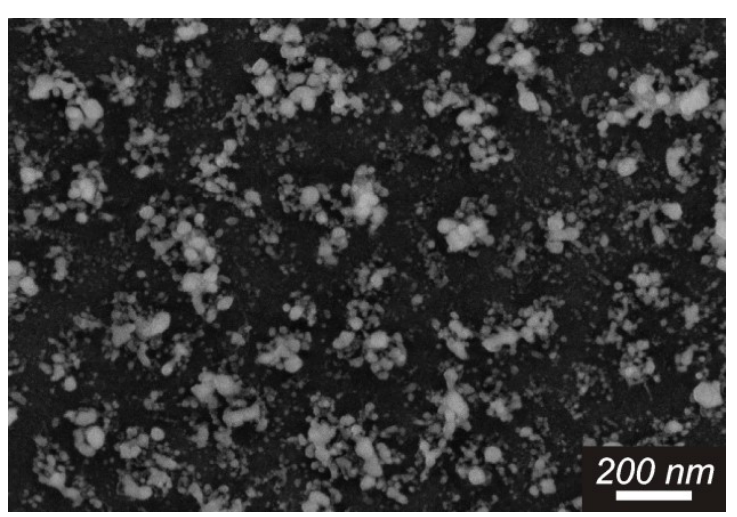

(b)

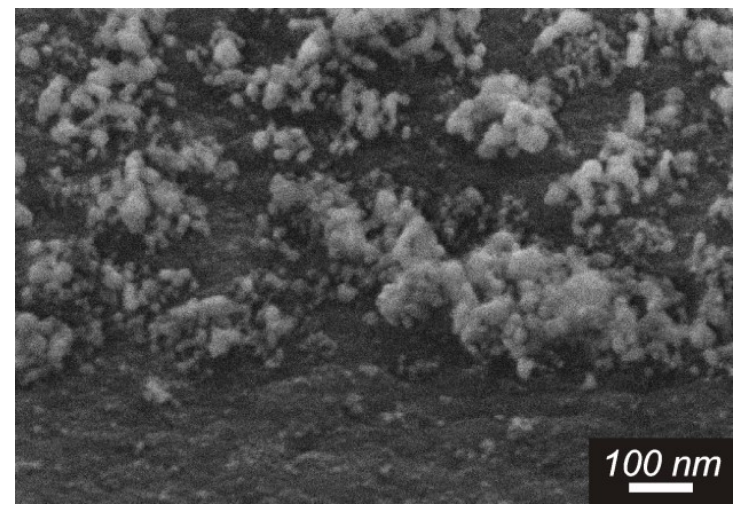

(d)

FIGURE 2. Surface morphology of carbon nanostructures deposited under various conditions: (a, c) $\mathrm{Ar} / \mathrm{CO}_{2}$ gases were injected through the single surfatron, and $\mathrm{CH}_{4}$ was transported via a parallel surfatron, (b, d) $\mathrm{Ar} / \mathrm{CO}_{2}$ gases were injected via 4 surfatrons and $\mathrm{CO}_{2} / \mathrm{CH}_{4}$ gases were introduced through the shower head.

CVD process [8]. The process conditions were as follows: $P=1700 \mathrm{~W}$, gas pressure $20 \mathrm{mbar}, \mathrm{H}_{2}$ flow $300 \mathrm{sccm}$, substrate temperature $T_{\mathrm{s}}=650^{\circ} \mathrm{C}$ and treatment time $10 \mathrm{~min}$. After the annealing process, the catalyst layer decomposed into small nickel clusters about $40 \mathrm{~nm}$ in diameter.

(3.) Deposition of carbon nanostructures, which was carried out using the modified plasma SWD PECVD system. The system was pumped to a base pressure of 0.008 mbar and was then maintained at a pressure of 0.2 mbar by introducing an Ar carrier gas at a flow rate of $100 \mathrm{sccm}$ and various ratios of $\mathrm{CO}_{2}$ and $\mathrm{CH}_{4}$. The flow of methane was changed from 60 to $90 \mathrm{sccm}$, while the flow of carbon dioxide was kept at a constant value of $30 \mathrm{sccm}$. A microwave power input of $300 \mathrm{~W}$ operated in the external modulation mode was used in all the experiments. Dur- 


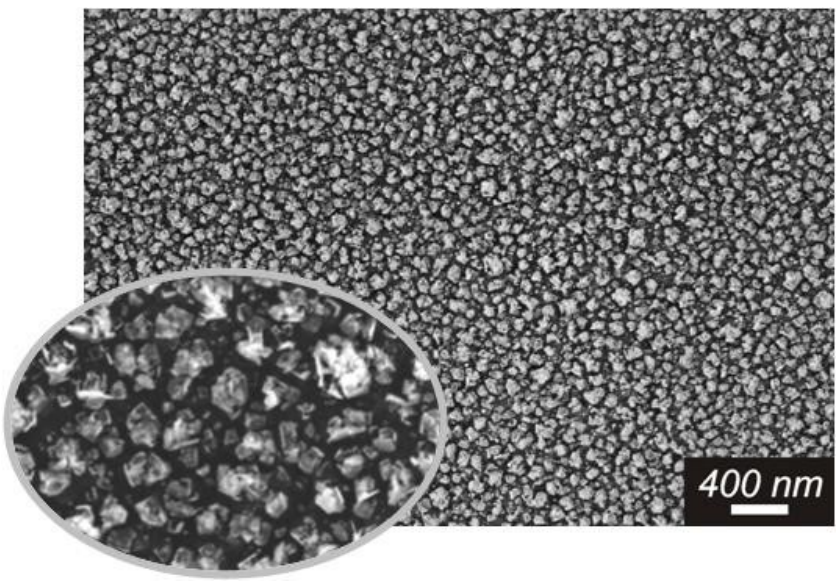

(a)

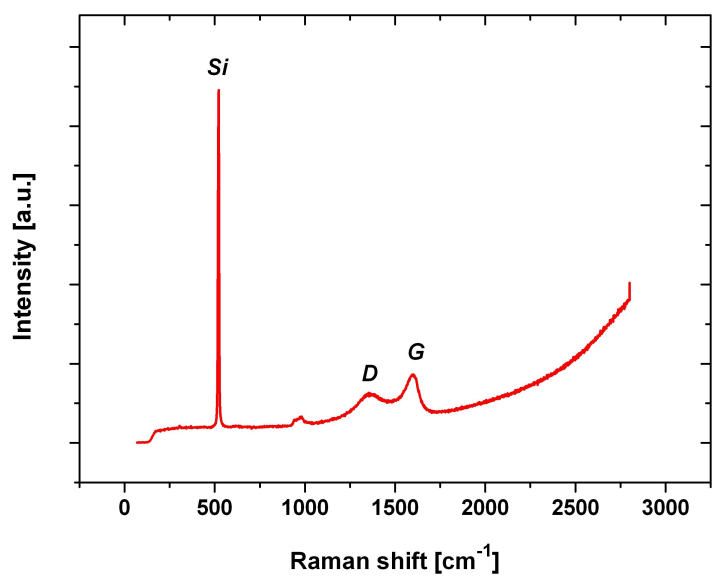

(b)

Figure 3. Top-view SEM image (a) and Raman spectrum (b) of carbon nanostructures deposited under the following conditions: $\mathrm{Ar} / \mathrm{CO}_{2}$ gases were injected through a single surfatron, and $\mathrm{CH}_{4}$ gas flowed through parallel surfatrons.

ing the deposition process the substrate temperature was maintained at $650{ }^{\circ} \mathrm{C}$ and the deposition time was $15 \mathrm{~min}$. The distance between substrate holder and precursor outlet was varied from 1 to $3 \mathrm{~cm}$.

\subsection{MATERIAL CHARACTERIZATION}

The surface morphology of the coatings (carbon nanostructures) was characterized by scanning electron microscopy (SEM e_LiNE writer, Raith $\mathrm{GmbH}$ ) and was confirmed by UV-Raman spectroscopy (Renishaw InVia Reflex Raman spectrometer, $442 \mathrm{~nm}$ excitation wavelength).

\section{Results And Discussion}

Figure 2 shows the surface morphology of carbon nanostructures deposited using various $\mathrm{CH}_{4} / \mathrm{CO}_{2}$ flow rates. The distance between substrate holder and quartz nozzle outlet was $1 \mathrm{~cm}$. The SEM images clearly confirm that only isolated nanoislands were formed using an $\mathrm{Ar} / \mathrm{CO}_{2} / \mathrm{CH}_{4}$ gas mixture $(100 / 30 / 60 \mathrm{sccm})$ (Figure 2ac). The surface morphology changed considerably after the $\mathrm{CH}_{4}$ gas flow was increased from 60 to $90 \mathrm{sccm}$ (Figure $2 \mathrm{pd}$ ). In this case, the SEM measurements indicate the development of nanotube-like structures. The Raman spectroscopy measurements did not reveal a reasonable signal of carbon phases.

Next we investigated the influence of sample position. The distance between substrate holder and precursor outlet increased to $3 \mathrm{~cm}$. As in the previous case, a gas mixture of $\mathrm{Ar} / \mathrm{CO}_{2} / \mathrm{CH}_{4}(100 / 30 / 60 \mathrm{sccm})$ was introduced to the chamber. The SEM image reveals the formation of a porous-like structure consisting of nanosized features (Figure $3 \mathrm{a}$ ). The Raman spectrum (Figure 3b) is represented by three strong contributions: the silicon characteristic peak centered at $520 \mathrm{~cm}^{-1}$ (Si-peak) and two broad bands centered at approximately $1350 \mathrm{~cm}^{-1}$, which is attributed to the $\mathrm{D}$ band, and at approximately $1590 \mathrm{~cm}^{-1}$, which is attributed to the $\mathrm{G}$ band. The $\mathrm{D}$ band is usually assigned to the disorder and imperfection of the carbon crystallites, whereas the $\mathrm{G}$ band is one of the two E2g modes of the stretching vibrations in the $\mathrm{sp}^{2}$ domains of perfect graphite [9]. In addition, a weak broad band resolvable at $970 \mathrm{~cm}^{-1}$ reflects the second-order peak of the Si substrate [10].

Increasing the methane flow from 60 to $90 \mathrm{sccm}$ in combination with varying the gas inlet(s) resulted in the formation of vertically ordered carbon nanowalls (Figure 4ab). The distance between substrate holder and precursor outlet was kept at $3 \mathrm{~cm}$. Figure 4 . shows the Raman spectrum of the nanostructures that formed. Four basic features are recognized in the Raman spectrum: a sharp Si peak centered at $520 \mathrm{~cm}^{-1}$, the $\mathrm{D}$ band $\left(1369 \mathrm{~cm}^{-1}\right)$, the $\mathrm{G}$ band $\left(1570 \mathrm{~cm}^{-1}\right)$, and the second-order $\mathrm{D}$ band (2D-band). The $2 \mathrm{D}$ band centered at $2720 \mathrm{~cm}^{-1}$ is attributed to the typical symbol of graphitic carbon [11-13. Moreover, it should be noted that the radial breathing mode (RBM) was not detected in any samples, i.e., absence of single or multiwall carbon nanotubes.

These results clearly confirm that various carbon nanostructures can be deposited by a surface wave discharge. The gas mixture and the working gas inlet to the process chamber were found to be the crucial parameters for the growth of various carbon forms/types. Increasing the $\mathrm{CH}_{4}$ concentration and using the shower head for introducing working gases into the chamber led to the formation of carbon nanowalls (Figure $4 \mathrm{ab}$ ). We found that reactive gases $\left(\mathrm{CO}_{2}\right.$ and $\mathrm{CH}_{4}$ ) are optimally decomposed at the substrate by Ar plasma due to a set of plasma-chemical reactions which finally support the growth of carbon nanostructures. Moreover, we found that the optimal distance for deposition of carbon nanostructures is $3 \mathrm{~cm}$ for our experimental SWD process. These observations represent unique and, in certain cases, advanced features of the surfatron system. 


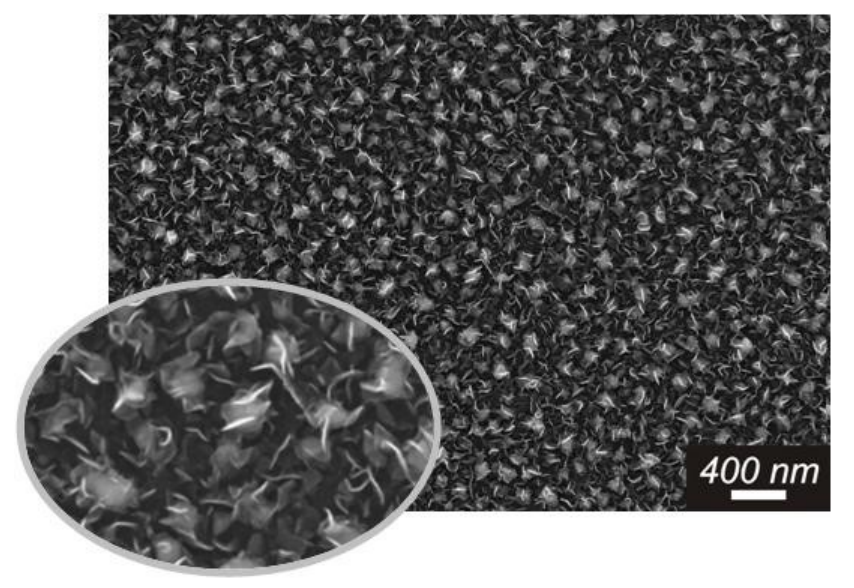

(a)

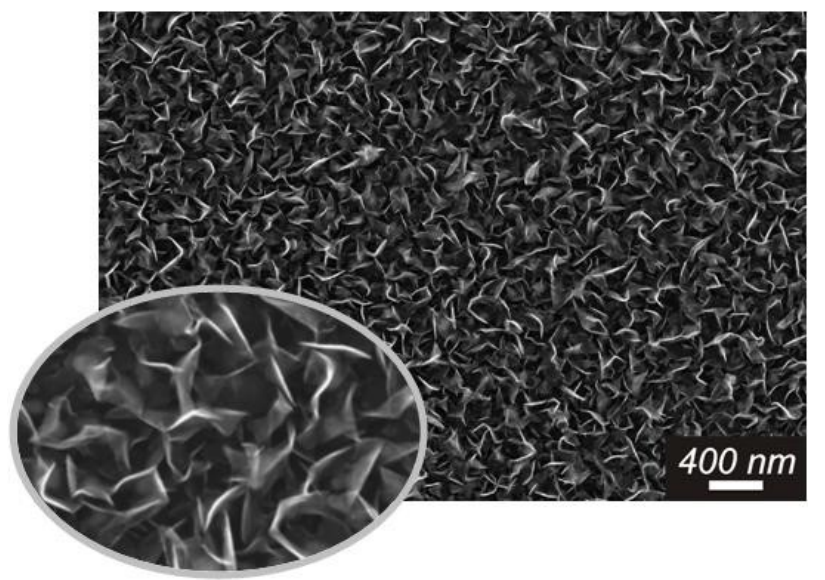

(b)

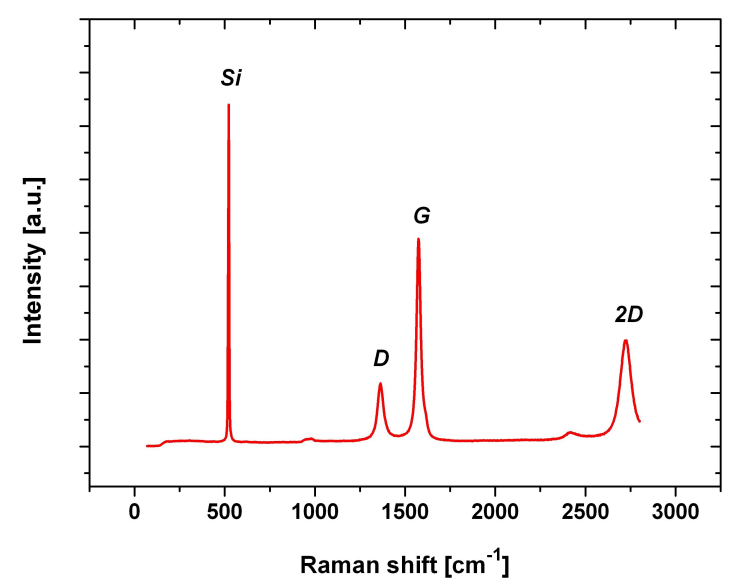

(c)

Figure 4. Top-view SEM images (a, b) and the Raman spectrum (c) of carbon nanostructures deposited under the following conditions: Ar gas was injected via 4 surfatrons, and $\mathrm{CO}_{2} / \mathrm{CH}_{4}$ gases were introduced through the shower head.

\section{Conclusions}

We have introduced the modified plasma enhanced CVD system working on the principle SWD as a versatile deposition system for the growth of various carbon nanostructures. We have shown that the carbon structures that are formed are significantly influenced by the gas mixture (i.e., ratios of $\mathrm{CO}_{2} / \mathrm{CH}_{4}$ ) and by the chosen gas inlet(s) for achieving the proper gas decomposition and/or plasma-chemically driven reactions at the substrate surface. The formation of carbon nanowalls was observed after the methane content was increased and its flow via the shower head was forced. We assume that the implementation of SWD will open new prospects in deposition of carbon allotrope forms, or even for gentle surface modification.

\section{ACKNOWLEDGEMENTS}

This work was supported by grants 14-06054P (Czech Science Foundation) and TA01011740 (Technological Agency of the Czech Republic).

\section{REFERENCES}

[1] Soppe, W. et al.: Bulk and surface passivation of silicon solar cells accomplished by silicon nitride deposited on industrial scale by microwave PECVD. Prog. Photovolt. Res. Appl., 13 (7), 2005, p. 551-569. DOI:10.1002/pip.611

[2] Ferreira, C.M. et al.: Air-water microwave plasma torch as a NO source for biomedical applications. Chem. Phys., 398, 2012, p. 248-254. DOI:10.1016/j.chemphys.2011.05.024

[3] Brewer, M.A. et al.: Simple, safe, and economical microwave plasma-assisted chemical vapor deposition facility. Rev. Sci. Instrum., 63 (6), 1992, p. 3389-3393. DOI:10.1063/1.1142557

[4] Takanishi, Y. et al.: Deposition of polycrystalline SiGe by surface wave excited plasma. Thin Solid Films, 516 (11), 2008, p. 3554-3557. DOI:10.1016/j.tsf.2007.08.025

[5] Kment, S. et al.: Photo-induced electrochemical functionality of the $\mathrm{TiO} 2$ nanoscale films.

Electrochimica Acta, 54 (12), 2009, p. 3352-3359. DOI:10.1016/j.electacta.2008.12.036

[6] Šerá, B. et al.: New Physicochemical Treatment Method of Poppy Seeds for Agriculture and Food Industries. Plasma Sci. Technol., 15 (9), 2013, p. 935. DOI:10.1088/1009-0630/15/9/19

[7] Olejníček, J. et al.: ZnO thin films prepared by surfatron produced discharge. Catal. Today, 230, 2014, p. 119-124. DOI:10.1016/j.cattod.2013.11.024 
[8] Kromka, A. et al.: Linear antenna microwave plasma CVD deposition of diamond films over large areas.

Vacuum, 86 (6), 2012, p. 776-779. DOI:10.1016/j.vacuum.2011.07.008

[9] Kruk, M. et al.: Partially graphitic, high-surface-area mesoporous carbons from polyacrylonitrile templated by ordered and disordered mesoporous silicas. Microporous Mesoporous Mater., 102, 2007, p. 178-187. DOI:10.1016/j.micromeso.2006.12.027

[10] Woo, H. K. et al.: Growth of epitaxial beta-SiC films on silicon using solid graphite and silicon sources. Diam. Relat. Mater., 8, 1999, p. 1737-1740. DOI:10.1016/S0925-9635(99)00016-3
[11] Krivchenko, V. A. et al.: Carbon nanowalls: the next step for physical manifestation of the black body rating. Sci. Rep., 3, 2013, p. 1-6. DOI:10.1038/srep03328

[12] Wang, L. et al.: B and $\mathrm{N}$ isolate-doped graphitic carbon nanosheets from nitrogen-containing ion-exchanged resins for enhanced oxygen reduction. Sci. Rep., 4, 2014, p. 1-8.

[13] Ghosh, S. et al.: Evolution and defect analysis of vertical graphene nanosheets. J. Raman Spectrosc., 45, 2014, p. 642-649. 